University of Wollongong

Research Online

Australian Institute for Innovative Materials -

Papers

Australian Institute for Innovative Materials

$1-1-2015$

Influence of biopolymer loading on the physiochemical and electrochemical properties of inherently conducting polymer biomaterials

Paul J. Molino

University of Wollongong, pmolino@uow.edu.au

Peter C. Innis

University of Wollongong, innis@uow.edu.au

Michael J. Higgins

University of Wollongong, mhiggins@uow.edu.au

Robert M. I Kapsa

University of Wollongong, robk@uow.edu.au

Gordon G. Wallace

University of Wollongong, gwallace@uow.edu.au

Follow this and additional works at: https://ro.uow.edu.au/aiimpapers

Part of the Engineering Commons, and the Physical Sciences and Mathematics Commons

Research Online is the open access institutional repository for the University of Wollongong. For further information contact the UOW Library: research-pubs@uow.edu.au 


\title{
Influence of biopolymer loading on the physiochemical and electrochemical properties of inherently conducting polymer biomaterials
}

\author{
Abstract \\ The physicochemical and electrochemical properties of polypyrrole (PPy) doped with the biological \\ dopant dextran sulphate (DS) were shown to be significantly altered as a function of varying the salt \\ concentration $(0.2,2$ or $20 \mathrm{mg} / \mathrm{ml})$ in the polymerisation electrolyte. Films grown in the presence of 0.2 \\ $\mathrm{mg} / \mathrm{ml}$ DS generated the highest potential during galvanostatic growth, with the potential decreasing with \\ each subsequent increase in DS concentration. The electroactivity of the polymers was similar for all \\ three DS concentrations, with the $20 \mathrm{mg} / \mathrm{ml}$ film drawing slightly more current upon reduction in PBS. \\ Increasing the DS concentration reduced film interfacial roughness and increased polymer hydrophilicity. \\ Polymer mass and thickness was larger for DS films grown from $0.2 \mathrm{mg} / \mathrm{ml}$ and $2 \mathrm{mg} / \mathrm{ml}$ DS electrolyte \\ solutions, compared to the $20 \mathrm{mg} / \mathrm{ml}$ films. The latter also demonstrated a much higher shear modulus \\ than the $2 \mathrm{mg} / \mathrm{ml}$ and $0.2 \mathrm{mg} / \mathrm{ml}$ films, respectively. The changes in the polymer physicochemical \\ properties were associated with an increase in polymer densification with increasing DS loading, \\ correlating with a likely higher conjugation generated during polymerisation at a potential closer to the \\ ideal oxidation potential of pyrrole. Herein we describe a facile approach through which polymer \\ properties may be varied significantly by varying the dopant concentration in the electrolyte, providing the \\ ability to tune polymer properties for enhanced functionality while preserving fundamental polymer \\ chemistry.

\section{Keywords} \\ polymer, conducting, inherently, properties, biomaterials, electrochemical, loading, influence, biopolymer, \\ physiochemical

\section{Disciplines} \\ Engineering | Physical Sciences and Mathematics

\section{Publication Details} \\ Molino, P. J., Innis, P. C., Higgins, M. J., Kapsa, R. M. I. \& Wallace, G. G. (2015). Influence of biopolymer \\ loading on the physiochemical and electrochemical properties of inherently conducting polymer \\ biomaterials. Synthetic Metals, 200 40-47.
}




\title{
Influence of Biopolymer Loading on the Physiochemical and Electrochemical Properties of Inherently Conducting Polymer Biomaterials
}

\author{
Paul J. Molino*, Peter C. Innis, Michael J. Higgins, Robert. M.I. Kapsa, Gordon G. \\ Wallace*
}

ARC Centre of Excellence for Electromaterials Science

Intelligent Polymer Research Institute,

University of Wollongong, Wollongong, NSW 2522, Australia

* Corresponding Author: Pau J. Molino, Gordon G Wallace

Tel: +61-2-4298 1449 (PJM); +61-2-4221 3127 (GGW)

Fax: +61-2-4221 3114 (PJM \& GGW)

Email address: pmolino@uow.edu.au; gordon_wallace@uow.edu.au 


\begin{abstract}
The physicochemical and electrochemical properties of polypyrrole (PPy) doped with the biological dopant dextran sulphate (DS) were shown to be significantly altered as a function of varying the salt concentration $(0.2,2$ or $20 \mathrm{mg} / \mathrm{ml})$ in the polymerisation electrolyte. Films grown in the presence of $0.2 \mathrm{mg} / \mathrm{ml} \mathrm{DS}$ generated the highest potential during galvanostatic growth, with the potential decreasing with each subsequent increase in DS concentration. The electroactivity of the polymers was similar for all three DS concentrations, with the $20 \mathrm{mg} / \mathrm{ml}$ film drawing slightly more current upon reduction in PBS. Increasing the DS concentration reduced film interfacial roughness and increased polymer hydrophilicity. Polymer mass and thickness was larger for DS films grown from $0.2 \mathrm{mg} / \mathrm{ml}$ and $2 \mathrm{mg} / \mathrm{ml}$ DS electrolyte solutions, compared to the $20 \mathrm{mg} / \mathrm{ml}$ films. The latter also demonstrated a much higher shear modulus than the $2 \mathrm{mg} / \mathrm{ml}$ and $0.2 \mathrm{mg} / \mathrm{ml}$ films, respectively. The changes in the polymer physicochemical properties were associated with an increase in polymer densification with increasing DS loading, correlating with a likely higher conjugation generated during polymerisation at a potential closer to the ideal oxidation potential of pyrrole. Herein we describe a facile approach through which polymer properties may be varied significantly by varying the dopant concentration in the electrolyte, providing the ability to tune polymer properties for enhanced functionality while preserving fundamental polymer chemistry.
\end{abstract}

Keywords: conducting polymer; polypyrrole; biopolymer; QCM; biomaterial 


\section{Introduction}

In the development of implantable bionic devices, a wide variety of polymeric systems directed at a suite of niche applications have been investigated in recent times. Polymer-based bionic systems' physical and chemical properties are readily tailored to specific needs, providing the potential to address diverse clinical criteria through regulation of cellular interactions and behaviour ${ }^{1}$. Of these, inherently conducting polymers (ICPs) have ignited particular interest due to their compatibility with a range of cell and tissue types, and their ability to perform multiple biologically related functions, including controlled delivery of drugs and biofactors ${ }^{2}$, guided cell growth ${ }^{3}$, and the electrical stimulation of cells and tissues $^{45}$. The ability to employ an array of polymer fabrication techniques provides the enormous flexibility to design and tailor ICP-based materials for particular applications, ranging from 2-dimensional films, nano- and micro-diameter fibres, hydrogels, and 3dimensional scaffolds assembled using one or several of the above components to form the final material architecture.

ICP synthesis is facilitated by the oxidation of the monomer unit, producing a positively charged conjugated polymer backbone. The positive charge along the length of the polymer chain is counter balanced by the inclusion of an anionic species, a process termed doping ${ }^{6}$. The choice of dopant is known to influence the physical and chemical properties of the ICP, with the incorporation of biological dopants shown to influence cellular interactions and add specific functionality to the polymer materials. For example, incorporation of extracellular matrix components as the dopant species in polypyrrole ICPs has been shown to support increased neurite outgrowth in PC12 cells compared to films with a synthetic dopant ${ }^{7}$, and the co-doping of polypyrrole with neurotrophin-3 protein has been shown to increase neurite outgrowth from explants via the enhanced release of the neurotrophin from the polymer during electrical stimulation ${ }^{8}$. 
Recently, attention has turned towards understanding the fundamental material properties that promote favourable polymer - biological interactions in an attempt to guide the development of the materials for targeted biofunctionality and biocompatibility. A number of studies have characterised ICP physicochemical properties as a function of the dopant species, and in turn attempted to correlate specific polymer characteristics with cellular behaviour on the polymer interface ${ }^{9,10}$. However there remains high variability within existing literature on specific polymerisation conditions employed during polymer synthesis, and often, evidence of a methodical approach to selecting or optimising polymerisation conditions is lacking. In particular, there has been no critical study of how modulating the concentration of large bioactive polyelectrolyte dopant species in the polymerisation electrolyte may influence biologically relevant polymer characteristics - a facile approach that may provide an avenue for further tailoring polymer properties for improved functionality. Herein we employ polypyrrole doped with a large biologically-relevant polyelectrolyte anion dopant with clinical application as an anticoagulant (dextran sulphate; DS) ${ }^{11}$, as a model system by which to illustrate modulation of biologically relevant polymer physicochemical and electrochemical properties by varying the salt concentration in the polymerisation electrolyte. Previously we have demonstrated that varying the DS loading of PPy-DS films and polymerisation time influences key interfacial polymer properties, thereby influencing the nature of protein - polymer interactions ${ }^{12}$. We extend this previous work, focusing exclusively on the influence of DS loading on several polymer physiochemical and electrochemical properties, and thereby providing a means by which to fine-tune ICP biomaterials for specific therapeutic applications. Furthermore, we present the quartz crystal microbalance with dissipation monitoring as a powerful and highly efficient technique with which to characterise the physical properties of electrochemically polymerised organic 
conducting polymers, including the measurement of dynamic processes during electrochemical stimulation.

\section{Experimental}

\subsection{General}

Pyrrole was purchased from Merck, purified by distillation and stored at $-18^{\circ} \mathrm{C}$. Dextran Sulfate sodium salt (D-6001) was purchased from Sigma-Aldrich. All other reagents were purchased from commercial houses and used as received.

\subsection{Electrochemical Polymerisation of Polymer Films}

Electrochemical polymerisation of conducting polymer films was performed using a Q-Sense Electrochemistry Module (QEM 401) axial flow cell with a Q-Sense E4 Quartz Crystal Microbalance system (Q-Sense AB, Västra, Frölunda, Sweden), allowing simultaneous QCM-D parameter recording of film properties during polymerisation. The QCM sensor was an A-T cut quartz crystal with a $10 \mathrm{~mm}$ diameter gold electrode (QSX301) with a fundamental resonance frequency of $5 \mathrm{MHz}$ (Q-Sense AB, Västra, Frölunda, Sweden). Prior to each experiment, the gold sensor surface upon the quartz crystal was cleaned with piranha solution (70\% sulphuric acid and 30\% hydrogen peroxide) for 3 min, and then rinsed thoroughly with deionised water and dried with nitrogen gas. Aqueous solutions for polymer synthesis consisted of $0.2 \mathrm{M}$ pyrrole in deionised water with $0.2 \mathrm{mg} / \mathrm{ml}, 2 \mathrm{mg} / \mathrm{ml} \mathrm{or} 20 \mathrm{mg} / \mathrm{ml}$ Dextran Sulfate. Each solution was deoxygenated for 10 mins via bubbling with nitrogen gas before use. The Q-Sense electrochemistry cell consisted of a platinum counter and a gold working electrode with a World Precision Instruments ${ }^{\circledR}$ Dri-Ref $^{\mathrm{TM}}$ reference electrode. PPyDS films were grown galvanostatically onto gold coated Q-Sense quartz sensors using an eDAQ e-corder 410 recorder and EA163 potentiostat connected to the Q-Sense 
electrochemistry module. Aqueous polymer growing solution was flowed through the electrochemistry module at $60 \mu 1 / \mathrm{min}$, and films grown at a current density of $0.25 \mathrm{~mA} / \mathrm{cm}^{2}$ for either 1 or 10 mins. The temperature within the E-module chamber during polymer polymerisation was kept constant at $22^{\circ} \mathrm{C}$ using the instrument software. Thereafter, the quartz sensors were removed from the E-cell and rinsed in distilled water and dried under a flow of nitrogen gas.

\subsection{Film Characterisation}

\subsubsection{Electroactivity}

PPy-DS films were polymerised for 10 mins using the Q-Sense electrochemistry module as described in section 2.2. Polymer films grown on the QCM sensors were then placed in an electrochemical cell containing a platinum mesh counter electrode, $\mathrm{Ag} \mid \mathrm{AgCl}$ reference electrode, and the PPy-DS film on the QCM sensor as the working electrode. PBS was employed as the electrolyte and 30 cyclic voltammograms (CVs) were undertaken using an eDAQ e-corder 410 recorder and EA163 potentiostat at a potential range of $\pm 500 \mathrm{mV}$ and scan rate of $20 \mathrm{mV} / \mathrm{s}$.

\subsubsection{Chemical Characterisation}

\subsubsection{Raman Spectroscopy}

Raman spectra were acquired using a JY HR-800 Raman spectrometer at $632 \mathrm{~nm}$ using a 300 line/mm grating and a x50 optical magnification.

\subsubsection{Physical Characterisation}

\subsubsection{Atomic Force Microscopy Topography}


The surface morphology of the polymer films were examined using a Mikromash NSC15 cantilever (spring constant $\sim 37 \mathrm{~N} / \mathrm{m}$ ) in Alternating Current (AC) mode with an MFP-3D AFM (Asylum Research, CA). Image scans of $5 \mu \mathrm{m}$ were obtained at a scan rate of $0.5 \mathrm{~Hz}$ in air. RRMS Roughness were calculated using Asylum Research Analysis software with the Igor Pro Software Package (WaveMetrics, OR).

\subsubsection{Quartz Crystal Microbalance with Dissipation Monitoring (QCM-D) Modelling of}

\section{Polymer Thickness and Shear Modulus}

Polymerisation of polymer films in-situ enabled the detailed analyses of the physical and mechanical properties of the polymer films using the QCM-D measurement parameters. QCM is an extremely sensitive mass sensing technique that in its simplest application can measure the mass of an adsorbed layer to the QCM sensor electrode surface through the application of the Sauerbrey equation ${ }^{13}$. As a material adsorbs to the sensor electrode surface, a decrease in the oscillating frequency of the sensor is recorded. The Sauerbrey relationship provides a linear correlation between the change in the resonance frequency of the oscillating crystal and the mass deposited on the sensor, with modern instruments reporting a sensitivity of $0.5 \mathrm{ng} / \mathrm{cm}^{2}$. However this relationship is dependent on the assumption that the coupled mass to the sensor is rigid (i.e. elastic), the mass is deposited evenly across the sensor surface and the mass load does not exceed $\sim 2 \%$ of the total quartz sensor mass. In the event that a mass deposited on the sensor exhibits inelastic or viscoelastic behaviour, the Sauerbrey relationship is inapplicable and more complicated models are required to extricate measurements from the resulting data set. The Q-tools software package v.3.0.10.286 (Biolin Sci, AB) was used to apply the Voigt model to determine layer thickness and shear modulus, using specific input parameters that provided the best data fit for the layer density $\left(1500 \mathrm{~kg} / \mathrm{m}^{3}\right)$, fluid density $\left(1020 \mathrm{~kg} / \mathrm{m}^{3}\right)$, layer viscosity $(0.0001 \leq 20 \mathrm{~kg} / \mathrm{ms})$, layer shear 
modulus $\left(10000 \leq 1^{10} \mathrm{~Pa}\right)$, and thickness $\left(1^{-9} \leq 1^{-6} \mathrm{~m}\right)$. The $5^{\text {th }}, 7^{\text {th }}$ and $9^{\text {th }}$ overtones were employed for all modelling calculations.

QCM-D study of the dynamic modulation of polymer thickness during cyclic voltammetry was performed by introducing PBS into the QCM-D electrochemistry module directly following PPy-DS film polymerisation. The $f$ and $D$ parameters were allowed to stabilise, and 30 cyclic voltammograms (CVs) were undertaken using an eDAQ e-corder 410 recorder and EA163 potentiostat at a potential range of $\pm 500 \mathrm{mV}$ and scan rate of $20 \mathrm{mV} / \mathrm{s}$. QCM-D data were recording during the application of cyclic voltammograms and the data modelled using the Q-tools software package with the modelling settings outlined above.

\subsubsection{Contact Angle Measurement}

The mean static contact angle measurements were performed using a DataPhysics optical contact angle goniometer. At least three measurements were undertaken on three separate films using deionised water droplets of $2 \mu l$ for each reported value.

\subsubsection{Scanning Electron Microscopy}

Scanning Electron Microscopy (SEM) imaging of polymer films was performed using a field emission SEM (JOEL JSM-7500FA). Polymer samples for SEM analysis were electrochemically grown on coverslips coated with 5nm Ti and 30nm Au. PPy-DS films were grown at $0.25 \mathrm{~mA} / \mathrm{cm}^{2}$ for 10 mins in a 3 electrode electrochemical cell using platinum mesh as the counter electrode, $\mathrm{Ag} \mid \mathrm{AgCl}$ reference electrode, and the $\mathrm{Ti} / \mathrm{Au}$ coated coverslip as the working electrode.

\section{Results \& Discussion}

\subsection{Raman Spectroscopy}


Raman and FTIR analysis of the deposited PPy-DS films at all DS concentrations resulted in near identical spectra (see supplemental). This finding was surprising given that in our earlier study XPS analysis showed an improvement in the observed levels of DS in the PPy, albeit at the immediate polymer surface layer probed by XPS. ${ }^{12}$ Raman has been shown to be an effective method of determining differences in conducting polymers' oxidation states. ${ }^{14}$ Although XPS confirmed an increase in the level of DS loading with increasing DS concentration during synthesis, the Raman spectrum of the deposited PPy-DS did not convey differences in polymer oxidation regardless of DS loading in the polymer. Raman spectra were further complicated by the problem that DS signals were obscured by those of PPy in each sample. These findings were consistent with the fact that all polymer films were grown to the same charge level resulting in relatively uniform or indistinguishable polymer oxidation states. Therefore, films grown in the presence of higher DS concentrations exhibited elevated incorporation of DS into the polymer matrix, as opposed to a specific enhancement of the doping of the PPy.

\subsection{Electrochemical Polymerisation and Electroactivity}

The potential generated during electrochemical polymerisation of PPy-DS polymer films at a constant current of $0.25 \mathrm{~mA} / \mathrm{cm}^{2}$ with varying concentrations of DS in the growing electrolyte solution are presented in Figure 1a. The potential generated immediately upon application of the current was by far the greatest for films grown at a DS concentration of $0.2 \mathrm{mg} / \mathrm{ml}(\sim 1.22$ $\mathrm{V})$, followed by $2 \mathrm{mg} / \mathrm{ml}(\sim 0.65 \mathrm{~V})$ and $20 \mathrm{mg} / \mathrm{ml}(\sim 0.55 \mathrm{~V})$. The potential gradually decayed for all three DS loading concentrations; however the relationship between the differing DS concentrations and the potential remained the same for the remainder of the polymer polymerisation $(0.2 \mathrm{mg} / \mathrm{ml}>2 \mathrm{mg} / \mathrm{ml}>20 \mathrm{mg} / \mathrm{ml})$. The observation of this high over- 
potential relationship strongly suggests that DS at lower dopant concentrations behaves as a poor supporting electrolyte for the initial growth of PPy. Previously an increase in counterion concentration in the electrolyte was shown to generate a higher density of charge during potentiostatic polymerisation of $\mathrm{PPy}^{15}$. Additionally, the growth potential used during polymer deposition was noted to have an influence upon the formation and the structure of the deposited polypyrrole; whereby films deposited at lower potentials resulted in a polymer with higher conjugation and electroactivity than those produced at higher potentials.

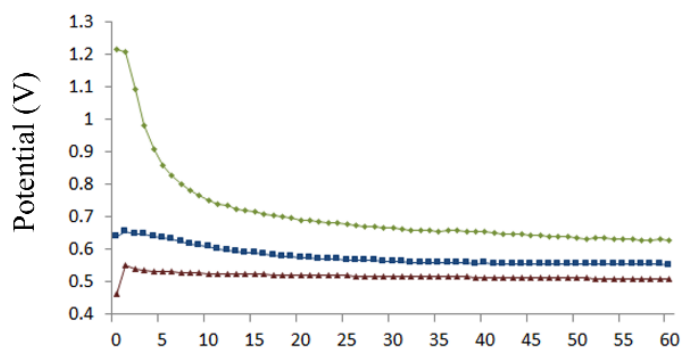

a.

Time (secs)

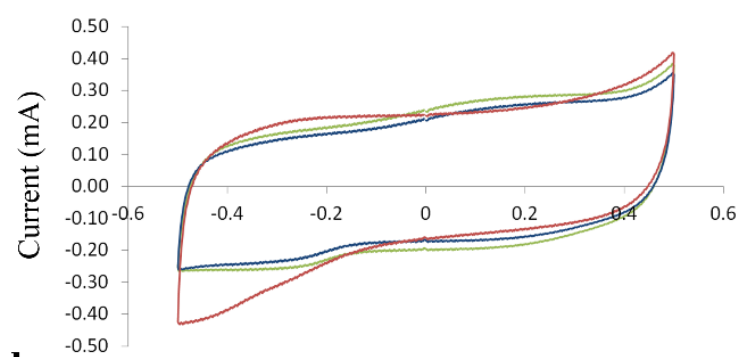

b.

Potential (V)

Figure 1. a. Potential (V) generated during electrochemical polymerisation of PPy doped with varying concentrations of DS in the electrolyte growing solution: $0.2 \mathrm{mg} / \mathrm{ml}$ (diamond/green); $2 \mathrm{mg} / \mathrm{ml}$ (square/blue); 20 $\mathrm{mg} / \mathrm{ml}$ (triangle/red). b. Cyclic Voltammograms (CV's) of PPy polymerised in the presence of $0.2 \mathrm{mg} / \mathrm{ml}$ (green), $2 \mathrm{mg} / \mathrm{ml}$ (blue) or $20 \mathrm{mg} / \mathrm{ml}$ (red) of the counterion DS. CVs were undertaken in PBS with the potential cycled between $+/-500 \mathrm{mv}$ at a scan rate of $20 \mathrm{mv} / \mathrm{s}$.

Cyclic Voltammograms of the PPy-DS biocomposites in PBS reveal the electroactivity of the PPy-DS films to be similar for all three DS loading concentrations grown to the same charge level (Figure 1b). Of the three films only those synthesised in the presence of $20 \mathrm{mg} / \mathrm{ml} \mathrm{DS}$ illustrated some deviation in electroactivity. This film was found to draw a greater current upon reduction of the polymer, reaching values of $-0.43 \mathrm{~mA}$ compared to both the $2 \mathrm{mg} / \mathrm{ml}$ and $0.2 \mathrm{mg} / \mathrm{ml}$ films that generate a current of $\sim-0.26 \mathrm{~mA}$ each (Figure 1b). This observation 
was consistent with the lower growth potential observed for these films where the growth potential was closest to the ideal oxidation potential of the pyrrole monomer.

\subsection{Physical Characterisation}

\subsubsection{Polymer Morphology, Roughness and Contact Angle}

We have previously reported on the influence of modulating the DS concentration in the polymerisation solution specifically on polymer morphology, topography and surface energy through which protein-polymer interactions were mediated ${ }^{12}$. These specific impacts on polymer properties are critical to the ability of the polymer to interface with cells and tissues, and are thus reiterated here. AFM topographic images of the various PPy-DS films are presented in Figure 2, with the $\mathrm{R}_{R M S}$ roughness values illustrated in Figure 3. The polymer films exhibit a nodular morphology that is characteristic of electrochemically polymerised polypyrrole films ${ }^{10,16}$. Smaller nodular features were demonstrated on the $1 \mathrm{~min}$ films, compared to the 10 min films for all three DS loading concentrations. For the 10 min films, the DS loading concentration of $0.2 \mathrm{mg} / \mathrm{ml}$ produced the films with highest $\mathrm{R}_{R M S}$ value of $40.2 \mathrm{~nm}$, followed by $2 \mathrm{mg} / \mathrm{ml}(30.9 \mathrm{~nm})$ and $20 \mathrm{mg} / \mathrm{ml}(10.2 \mathrm{~nm})$, respectively (Figure 3a). A similar trend was observed for the 1 min films, with $R_{R M S}$ values of $11.1 \mathrm{~nm}, 8.3 \mathrm{~nm}$ and $3.7 \mathrm{~nm}$ for the DS loading at $0.2 \mathrm{mg} / \mathrm{ml}, 2 \mathrm{mg} / \mathrm{ml}$ and $20 \mathrm{mg} / \mathrm{ml}$, respectively.

The general nodular polymer morphology reported here is comparable to previous studies of PPy-DS films polymerised under similar conditions ${ }^{9,10}$. Increasing the polymerisation time from 1 to 10 mins increased surface roughness considerably for all three DS loading concentrations, and is consistent with reports of increasing film roughness with increasing polymerisation time for variously doped PPy films ${ }^{16,17}$. Our finding that an increase in the DS concentration in the polymerisation solution resulted in a decrease in RMS roughness is in contrary to previous studies that reported an increase in polymer roughness with an increase 
in dopant concentration in the polymerisation electrolyte ${ }^{16}$. Other studies where monomer/counterion ratios in the polymerisation electrolyte were modulated have provided varying effects on polymer roughness for PPy films. An increase in the concentration of the counter ion p-toluenesulfonate $(0.0025 \mathrm{M}$ to $0.1 \mathrm{M})$ was found to increase surface roughness of the resulting electrochemically polymerised films, while an increase in the monomer/dopant concentration of PPy with poly(styrenesulfonate) resulted in an increase in surface roughness ${ }^{18}$. The influence of the counterion concentration on surface roughness is highly dependent on the specific anion employed during synthesis and has been reported by others. $^{19}$

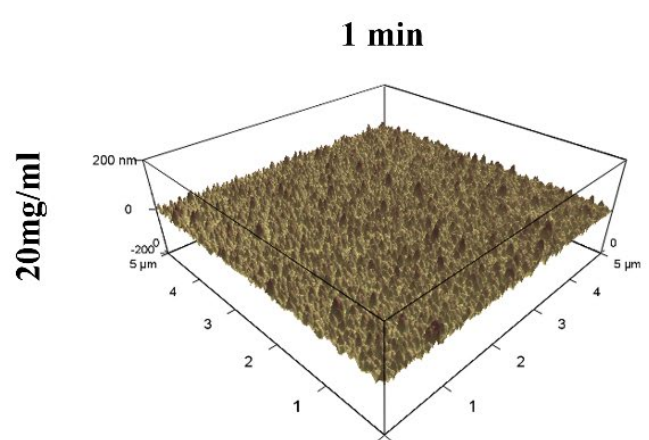

a.

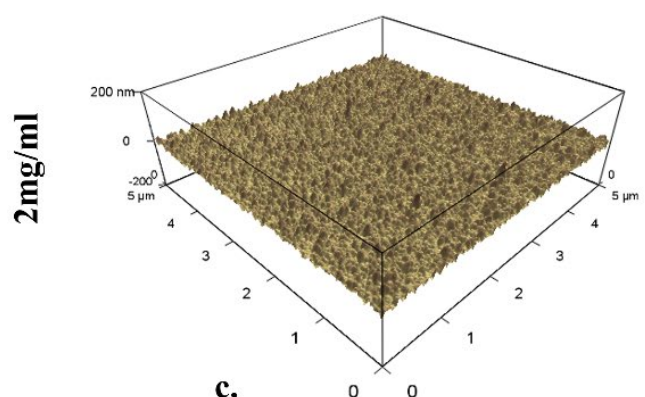

c.

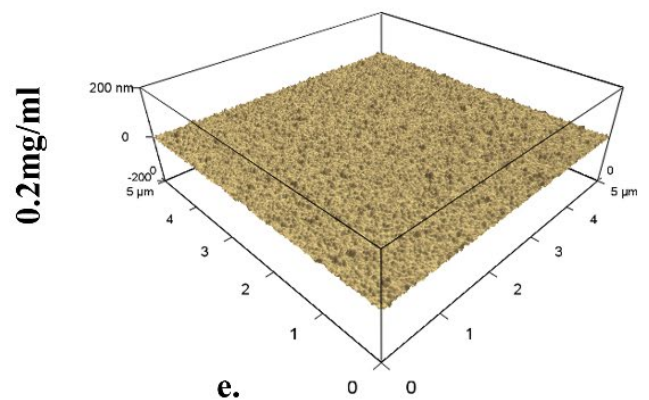

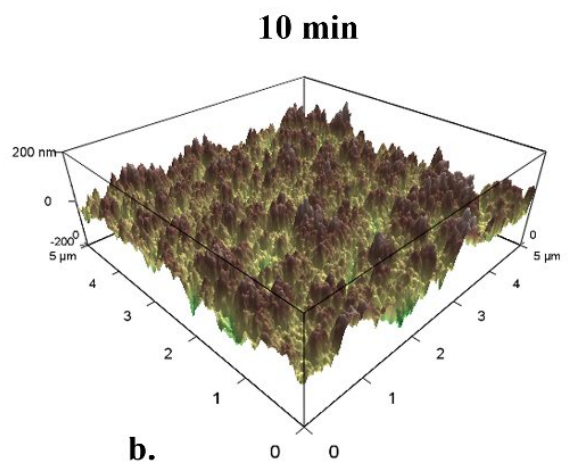

b.
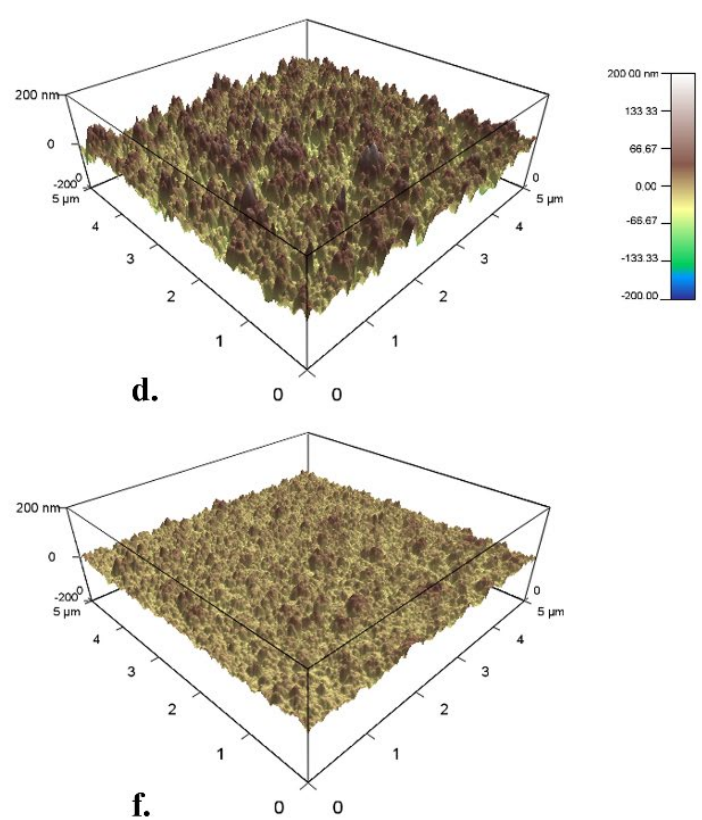

Figure 2. 3-dimensional AFM height profiles $(5 \mu \mathrm{m} \times 5 \mu \mathrm{m})$. a. $0.2 \mathrm{mg} / \mathrm{ml}(1 \mathrm{~min})$ b. $0.2 \mathrm{mg} / \mathrm{ml}(10 \mathrm{~min})$ c. 2 $\mathrm{mg} / \mathrm{ml}(1 \mathrm{~min})$ d. $2 \mathrm{mg} / \mathrm{ml}(10 \mathrm{~min})$ e. $20 \mathrm{mg} / \mathrm{ml}(1 \mathrm{~min})$ f. $20 \mathrm{mg} / \mathrm{ml}(10 \mathrm{~min})$. 


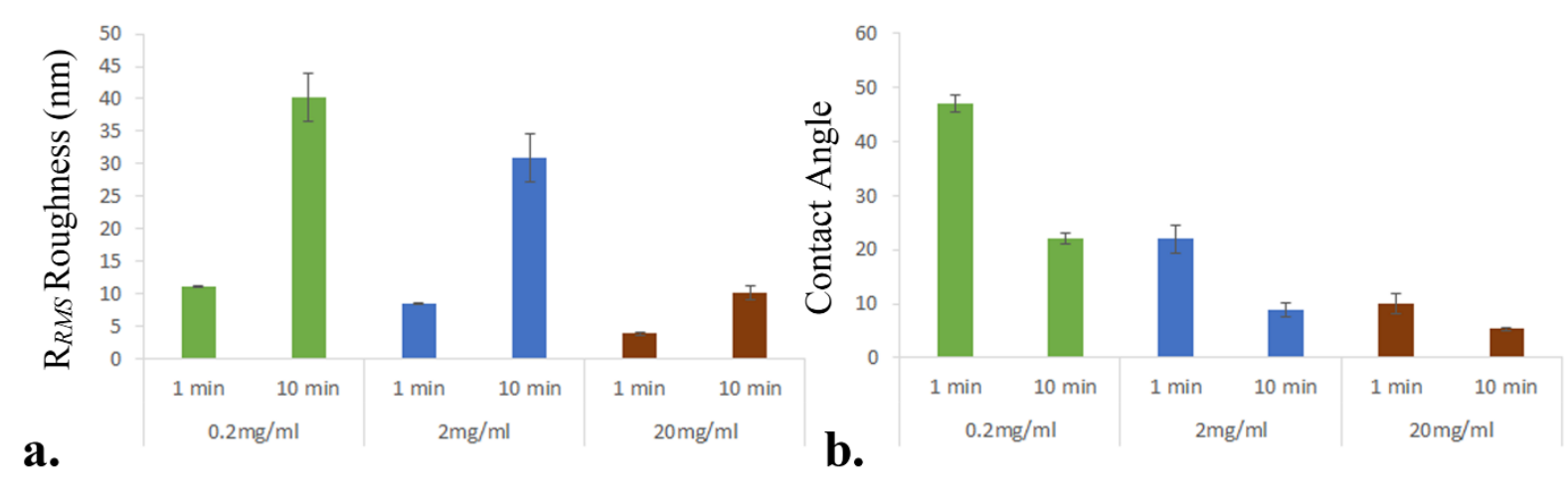

Figure 3. (a). Random Mean Square Roughness $\left(\mathrm{R}_{\mathrm{RMS}}\right)(\mathrm{nm})$ and (b) static contact angle measurements for 1 and 10 min films for each PPy-DS DS loading concentration. Error bars represent $95 \%$ confidence intervals surrounding the mean.

Static water contact angle measurements revealed significant differences in the wettability of the biocomposites, with interfacial surface energy increasing with an increase in both the DS loading concentration and polymerisation time (Figure $3 \mathrm{~b}$ ). The $1 \mathrm{~min}$ films demonstrated static contact angle measurements of $47^{\circ}, 22^{\circ}$ and $10^{\circ}$, while $10 \mathrm{~min}$ films provided values of $22^{\circ}, 9^{\circ}$ and $5^{\circ}$, for DS loading concentrations of $0.2 \mathrm{mg} / \mathrm{ml}, 2 \mathrm{mg} / \mathrm{ml}$ and $20 \mathrm{mg} / \mathrm{ml}$, respectively. XPS analysis of the studied films ${ }^{12}$ revealed an increase in the DS salt concentration in the polymerisation solution to lead to an increase in DS entrapment within the polymer matrix, and therefore an increase in sulfonation of the polymer interface. It is well known that surface sulphonation increases surface hydrophilicity through the introduction of sulfonic acid groups, with this mechanism likely operative here. In addition, an increase in surface roughness has been demonstrated to enhance the hydrophilicity of hydrophilic surfaces ${ }^{20}$, a trend that is illustrated here for all three biocomposites.

\subsubsection{Mass, Shear Modulus and Thickness}

Monitoring the polymerisation of the polymers in-situ using the QCM-D allowed fundamental material properties to be investigated. Figure 4 illustrates the modelled results for polymer mass, shear modulus and thickness for $10 \mathrm{~min}$ films from each PPy-DS 
biocomposite. Minor variations in the frequency and dissipation data outputs for $1 \mathrm{~min}$ films from all DS loading concentrations were found to generate considerable deviations in the modelling results between samples, and thus due to the difficulty in application of the model to this data they were not included in the modelled data set, and only the 10 min films were used to characterise the global properties of each polymer composite. The mass of polymer deposited during polymerisation for both the $0.2 \mathrm{mg} / \mathrm{ml}$ and $2 \mathrm{mg} / \mathrm{ml} \mathrm{DS}$ bioloading concentrations were similar, illustrating values of $127 \pm 23 \mu \mathrm{g} / \mathrm{cm}^{2}$ and $120 \pm 2 \mu \mathrm{g} / \mathrm{cm}^{2}$, respectively, with the highest DS loading $(20 \mathrm{mg} / \mathrm{ml})$ demonstrating significantly lower total film mass $\left(66 \pm 7 \mu \mathrm{g} / \mathrm{cm}^{2}\right)$. The shear modulus increased with DS loading, with the $0.2 \mathrm{mg} / \mathrm{ml}$ films illustrating the lowest shear modulus of $174 \pm 6 \mathrm{MPa}$, followed by $2 \mathrm{mg} / \mathrm{ml}(420 \pm 21$ $\mathrm{MPa}$ ) and the $20 \mathrm{mg} / \mathrm{ml}$ films which demonstrated the highest shear modulus of $769 \pm 100$ MPa (Figure 5). Conversely, the modelled thickness of the polymer films exhibited a general decrease with increasing DS loading, with $0.2 \mathrm{mg} / \mathrm{ml}, 2 \mathrm{mg} / \mathrm{ml}$, and $20 \mathrm{mg} / \mathrm{ml}$ films illustrating average height values of $850 \pm 153 \mathrm{~nm}, 803 \pm 14 \mathrm{~nm}$ and $465 \pm 47 \mathrm{~nm}$, respectively.
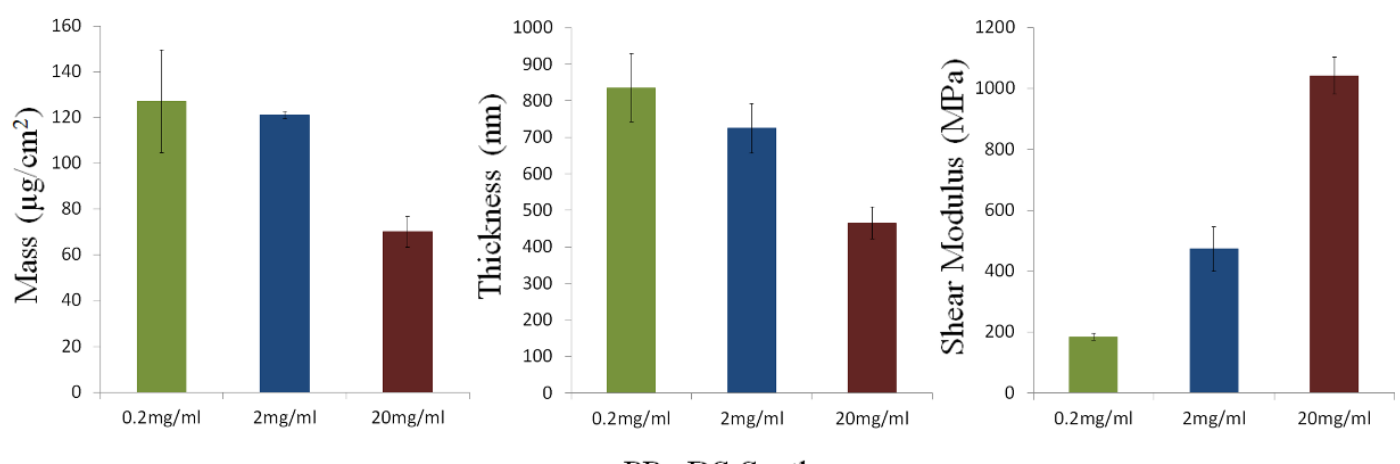

PPy-DS Syntheses

Figure 4. Mass (a) Shear Modulus (b) and Height (c) values for PPy-DS films of varying biodopant concentration, modelled from QCM-D data using the Voigt Model. Error bars represent 95\% confidence intervals around the mean. 
The efficacy of the Voigt modelling of polymer physical and mechanical properties was supported by optical profilometry measurements of thickness (data not shown), as well as converted elastic modulus measurements using force spectroscopy mode AFM (See Supplementary Information), of the modelled polymer films. The reduction in film thickness with increasing DS loading is contrary to previous reports of PPy/pTS films grown galvanostatically at $2 \mathrm{~mA} / \mathrm{cm}^{2}$ where thickness increased as a function of increasing pTS concentration in the aqueous polymerisation media ${ }^{16}$.

While increasing the DS loading resulted in a reduction in polymer mass and thickness, the opposite was evident for the shear modulus, which increased significantly. The nature of the dopant species is known to significantly influence the modulus of the resulting polymer ${ }^{10,21}$. Previous studies of PPy synthesised with a range of polyelectrolyte dopants, including DS, demonstrated considerable variation in the mechanical properties of the polymers, with the Young's modulus ranging from $30-1000 \mathrm{MPa}^{10}$. In another study increasing the concentration of the counterion pTS in PPy aqueous polymerisation media resulted in a decrease in the modulus of the polymer film ${ }^{22}$.

These findings of decreasing polymer mass/thickness and increasing shear modulus with increasing DS loading suggest that there is a significant densification of the PPy-DS as the DS concentrations reach levels where it acts more effectively as a supporting electrolyte permitting the uniform deposition of polymer. The more effective deposition is further illustrated by the lowering of the growth oxidation potential with increasing DS concentration.

The QCM-D technique measures both the mass of the polymer deposited on the electrode, as well as solvent entrapped within the polymer matrix. The reduction in the observed mass is indicative of less solvent, and subsequently electrolyte, being entrapped within the polymer 
when in solution as it densified under more optimal deposition conditions. SEM imaging of 10 min polymer films (Figure 5) demonstrates a clear decrease in the porosity, as well as the roughness (consistent with AFM measurements) of the films as the DS loading increases, supporting the view that the measured increase in mass for the $0.2 \mathrm{mg} / \mathrm{ml}$ and $2 \mathrm{mg} / \mathrm{ml} \mathrm{films}$ may largely be driven by hydration of the polymer films in solution. The decrease in polymer density and increase in hydration as DS loading decreases also provides a mechanism for the decrease in shear modulus with decreasing DS concentration (decrease in polymer density). Additionally, QCM-D study of the actuation of the PPy-DS films during cyclic voltammetry demonstrated a significant increase in the actuation presented by the $0.2 \mathrm{mg} / \mathrm{ml} \mathrm{films,}$ compared to both the $2 \mathrm{mg} / \mathrm{ml}$ and $20 \mathrm{mg} / \mathrm{ml}$ biodoped films (Figure 6). We propose this further supports the proposition of increased hydration of the film as biodopant loading decreases, with the highly porous $0.2 \mathrm{mg} / \mathrm{ml} \mathrm{DS}$ loaded films more readily allowing ion exchange with the electrolyte, and therefore providing for enhanced hydration/dehydration, and therefore actuation, of the polymer. 


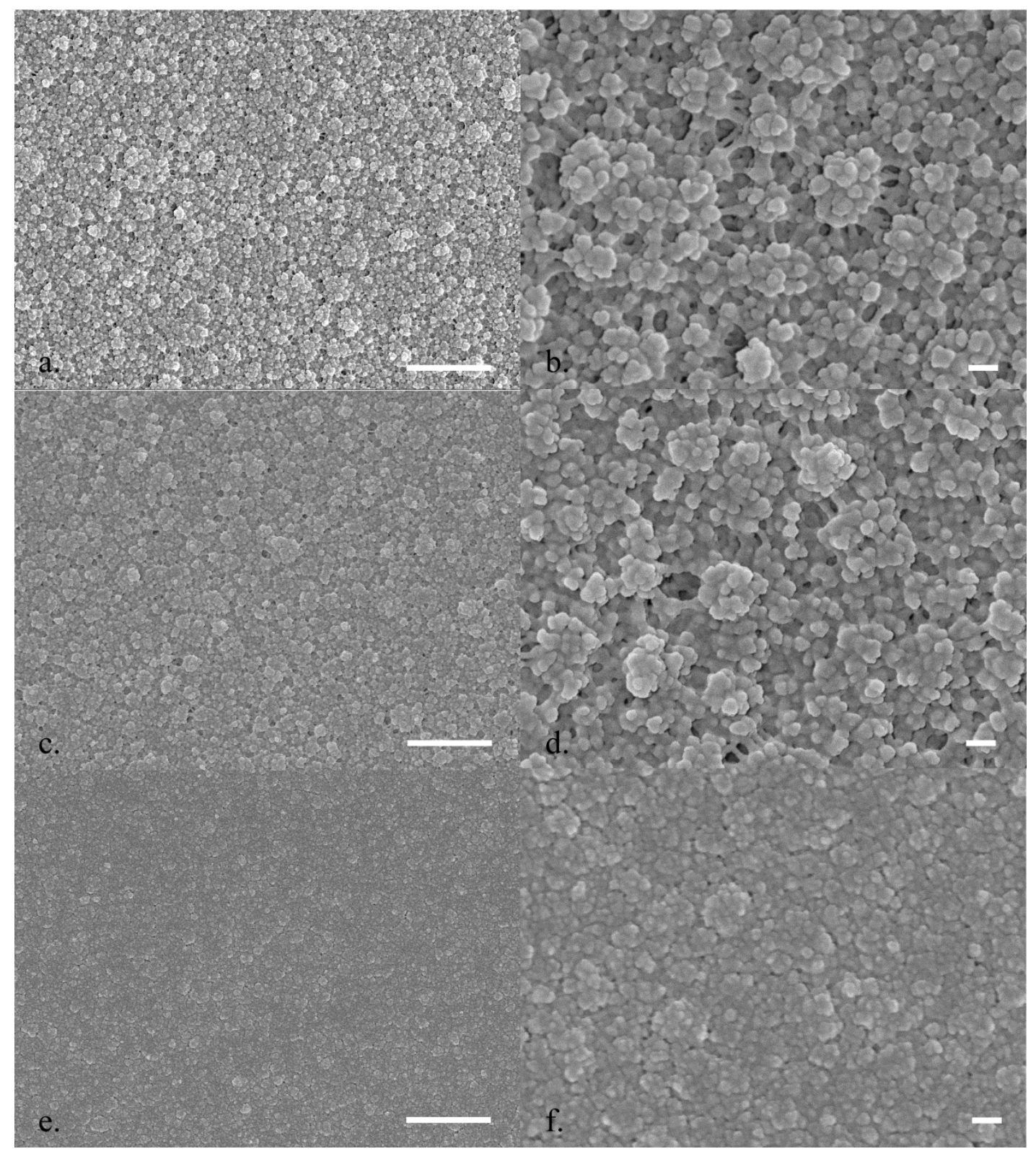

Figure 5. Low and high magnification SEM images of 10 min PPy-DS films polymerised with DS

concentrations of $0.2 \mathrm{mg} / \mathrm{ml}(\mathrm{a}, \mathrm{b}), 2 \mathrm{mg} / \mathrm{ml}$ (c,d) and $20 \mathrm{mg} / \mathrm{ml}$ (e,f). (Scale bar: $1 \mu \mathrm{m}$ for a,c,e; $100 \mathrm{~nm}$ for b,d,f.) 

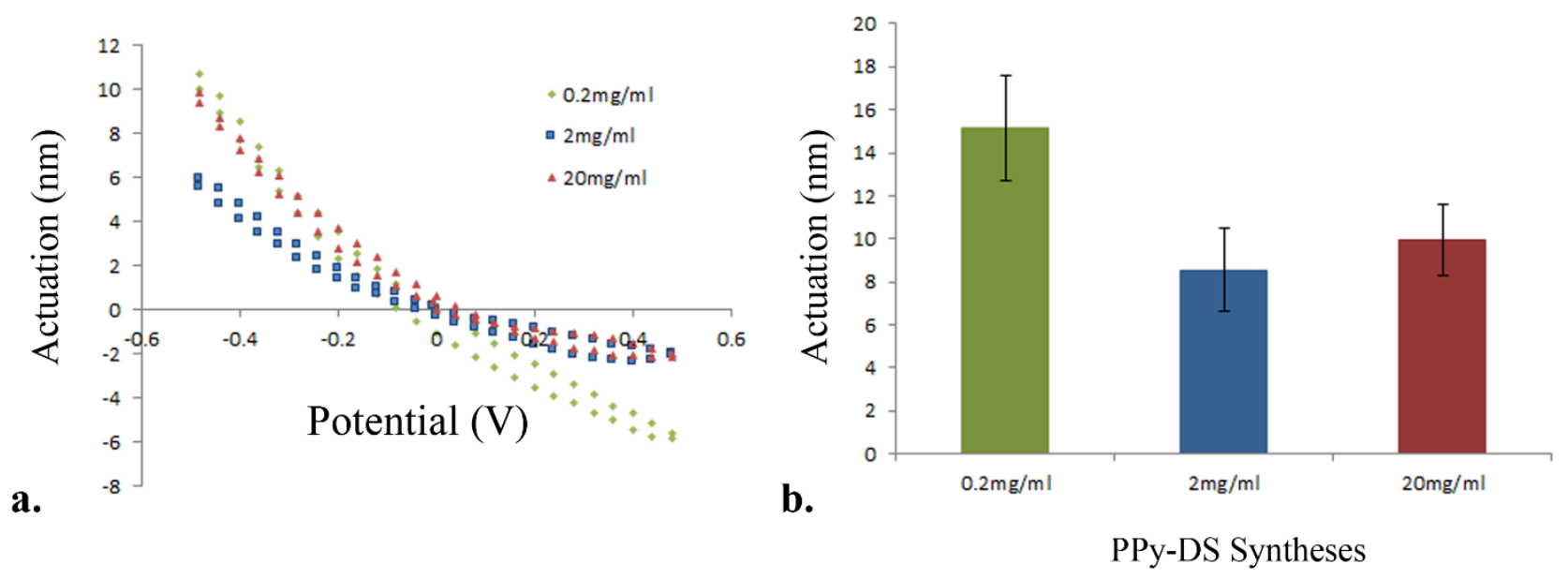

Figure 6. a. Actuation of PPy-DS polymers with different DS loading levels as a function of the potential during cyclic voltammograms. b. Mean maximum actuation generated during CV analyses of PPy-DS for each DS loading concentration. Error bars represent $95 \%$ confidence intervals around the men.

\subsection{Tuning Polymer Characteristics for Biomedical Applications}

Material interfacial properties such as roughness, wettability, elastic modulus and chemistry are critical for promoting favourable interactions that allow proper interfacing between the material and biomolecules, cells and tissues. Recently we demonstrated that modulating the concentration of the anion DS in the polymerising electrolyte and polymerisation time had a significant effect on the nature of protein interactions with the PPy-DS polymer surface, influencing the conformation of the surface bound protein, and thus the bioactivity of the proteinaceous conditioning film ${ }^{12}$. This variation in the protein-polymer interactions was attributed to changes in polymer surface roughness, wettability and chemistry that are likely to considerably influence subsequent cellular interactions with the polymer surface.

The ability to modulate polymer physicochemical properties while retaining a given fundamental polymer chemistry provides enormous scope to tune materials for improved functionality for many applications. Controlling the wettability of bio-doped ICP materials 
holds significant potential for applications such as sensing, microfluidics, filtration, and could also be employed to control protein and cellular adhesion. Substrate modulus is known to be critical for promoting beneficial cellular processes and behaviours ${ }^{23}$. Several studies have investigated ICP-cell interactions with cell types known to be sensitive to the mechanical properties of the underlying substrate. However in these studies, the moduli of the ICP polymers were controlled by varying the synthetic and biological dopants, thereby possibly introducing other properties (eg surface energy/chemistry) as key modulators of the observed biological behaviour. The method of varying the salt concentration to provide a more desirable nanomechanical environment at the polymer interface would provide a facile approach to improving polymer function for such applications.

Recent studies to realise the potential of electrical stimulation to control fundamental cellular interactions with implantable ICP-based scaffolds, have focused on providing appropriately bio-intuitive nano and micro-environments. Specifically, these environmental effects involve defined topographic, chemical and electrical cues to support the development of the desired tissue type. The ability to controllably modulate critical polymer physicochemical properties, while preserving the electroactivity of the ICP as demonstrated in this study, provides an excellent opportunity for understanding the complex relationship between biomimetic physiochemical and electrochemical stimuli on cells and tissues.

\section{Conclusion}

This study demonstrates that the physicochemical and electrochemical properties of ICP biomaterials can be vastly modified by varying the polymerisation time, as well as the concentration of the salt species in the polymerisation electrolyte. Previously we have illustrated that modifying the DS loading and polymerisation time for PPy-DS films impacted significantly on the mass and conformation of protein bound to the polymer surface. Here, 
we illustrate that modulating the salt concentration can be employed to control fundamental polymer properties, including polymer film mass, thickness, interfacial roughness, wettability, electroactivity and porosity; thereby providing a mechanism that allows the tuneability of polymer properties while retaining the fundamental polymer chemistry. This provides a straightforward approach by which ICP biomaterial properties may be finely tuned for a diverse array of applications.

\section{Acknowledgements}

The authors gratefully acknowledge the Australian Research Council and the National Health and Medical Research Council (Grant No. 573430). We also acknowledge the Australian National Nanofabrication Facility (ANFF) for access to equipment. The authors acknowledge the use of the facilities and the assistance of Mr Tony Romeo at the UOW Electron Microscopy Centre.

\footnotetext{
${ }^{1}$ Wang, S.; Lu, L.; Wang, C.; Gao, C.; Wang, X. Polymeric biomaterials for tissue engineering applications 2011. International Journal of Polymer Science 2011, doi:10.1155/2011/184623
}

${ }^{2}$ Richardson, R.T,; Thompson, B,; Moulton, S,; Newbold, C,; Lum, M.G,; Cameron, A. The effect of polypyrrole with incorporated neurotrophin-3 on the promotion of neurite outgrowth from auditory neurons. Biomat. 2007, 28(3), $513-523$.

${ }^{3}$ Breukers, R.D,; Gilmore, K.J,; Kita, M,; Wagner, K.K,; Higgins, M.J,; Moulton, S.E,; Clark, G.M,; Officer, D.L; Kapsa, R.M,; Wallace, G.G. Creating conductive structures for cell growth: growth and alignment of myogenic cell types on polythiophenes. J. Biomed. Mater. Res. A 2010, 95(1), 256 - 268.

${ }^{4}$ Schmidt, C.E,; Shastri, V.R,; Vacanti, J.P,; Langer, R. Stimulation of neurite outgrowth using electrically conducting polymer. Proc. Natl. Acad. Sci. USA 1997, 94(17), 8948 - 8953.

${ }^{5}$ Quigley, A.F.; Razal, J.M.; Thompson, B.C.; Moulton, S.E.; Kita, M.; Kennedy, E.L.; Clark, G.M.; Wallace, G.G.; Kapsa, R.M.I. A conducting polymer platform with biodegradable fibers for stimulation and guidance of axonal growth. Advanced Materials 2009, 21, 4393 4397.

${ }^{6}$ Wallace, G.G,; Spinks, G.M,; Kane-Maguire, L.A.P,; Teasedale, P.R. editors. Conductive electroactive polymers. 3rd Ed. CRC Press; 2009. 
${ }^{7}$ Green, R.A,; Lovell, N.H,; Poole-Warren, L.A. Cell attachment functionality of bioactive conducting polymers for neural interfaces. Biomat. 2009. 30, 3637 - 3644.

${ }^{8}$ Thompson, B.C,; Moulton, S.E.; Richardson, R.T,; Wallace. G.G. Effect of the dopant anion in polypyrrole on nerve growth and release of a neurotrophic protein. Biomat. 2011, 32, $3822-3831$.

${ }^{9}$ Gilmore, K.J,; Kita, M,; Han, Y,; Gelmi, A,; Higgins, M.J,; Moulton, S.E,; Clark, G.M,; Kapsa, R,; Wallace, G.G. Skeletal muscle cell proliferation and differentiation on polypyrrole doped with extracellular matrix components. Biomat. 2009, 30(29), 5292 - 5304.

${ }^{10}$ Gelmi, A,; Higgins M.J,; Wallace, G.G. Physical surface and electromechanical properties of doped polypyrrole biomaterials. Biomat. 2010, 31, $1974-83$.

${ }^{11}$ Hall, M,; Ricketts, C.R. The use of dextran sulphate as a blood anticoagulant in biological research. J. Clin. Pathol. 1952, 5, 366.

${ }^{12}$ Molino, P.J.; Higgins, M.J.; Innis, P.C.; Kapsa, M.I.; Wallace, G.G. Fibronectin and Bovine Serum Albumin Adsorption and Conformational Dynamics on Inherently Conducting Polymers: A QCM-D Study. Langmuir 2012, 28, 8433 - 8445.

${ }^{13}$ Sauerbrey, G. Z. Verwendung von schwingquarzen zur wägung dünner schichten und zur mikrowägung. Z. Phys. 1959, 155, $206-222$.

${ }^{14}$ Liu Y-C. Characteristics of vibration modes of polypyrrole on surface-enhanced Raman scattering spectra. J. Electroanal. Chem. 2004, 571, 255-264.

${ }^{15}$ Almario, A.A,; Caceres, R.L. Study of kinetic formation and the electrochemical behaviour of polypyrrole films. J. Chil. Chem. Soc. 2009, 54(1), 14-19.

${ }^{16}$ Kaynak, A. Effect of synthesis parameters on the surface morphology of conducting polymer films, Mat. Res. Bull. 1997, 32(3), $271-285$.

${ }^{17}$ Fonner, J.M,; Forciniti, L,; Nguyen, H,; Byrne, J.D,; Kou, Y-F,; Syeda-Nawaz, J,; Schmidt, C.E. Biocompatibility implications of polypyrrole synthesis techniques. Biomed. Mater. 2008, 3(3), doi:10.1088/1748-6041/3/3/034124.

${ }^{18}$ Gomez, N,; Lee, J.Y,; Nickels, J.D; Schmidt, C.E. Micropatterned Polypyrrole: A combination of electrical and topographical characteristics for the stimulation of cells. $A d v$. Func. Mat. 2007, 17(10), 1645 - 1653.

${ }^{19}$ Silk, T,; Hong, Q; Tamm, J,; Compton, R.G. AFM studies of polypyrrole film surface morphology I. The influence of film thickness and dopant nature. Synth. Met. 1998, 93, 5964.

${ }^{20}$ Irie, H,; Ping, T.S,; Shibata, T,; Hashimoto, K. Reversible control of wettability of a $\mathrm{TiO}_{2}$ Surface by Introducing Surface Roughness. Electrochemical and Solid-State Letters 2005, 8(9), doi:10.1149/1.1979455. 
${ }^{21}$ Fonner, J.M,; Schmidt, C.E,; Ren, P. A combined molecular dynamics and experimental study of doped polypyrrole. Polymer 2010, 51, 4985 - 4993.

${ }^{22}$ Kaynak, A,; Rintoul, L, George, G.A. Change of mechanical and electrical properties of polypyrrole films with dopant concentration and oxidative aging. Materials Research Bulletin 2000, 35, 813-824.

${ }^{23}$ Engler,; A.J,; Griffin, M.A,; Sen, S,; Bonnemann, C.G,; Sweeney, H.L,; Discher. D.E. Myotubes differentiate optimally on substrates with tissue-like stiffness: pathological implications for soft or stiff microenvironments. Journal of Cell Biology 2010, 166 (6), 877 887. 


\section{Supplementary Section.}

Supplemental Figure A. Raman spectra of PPy DS grown to the same charge at 0.2, 2 and $20 \mathrm{mg} / \mathrm{mL}$ DS.

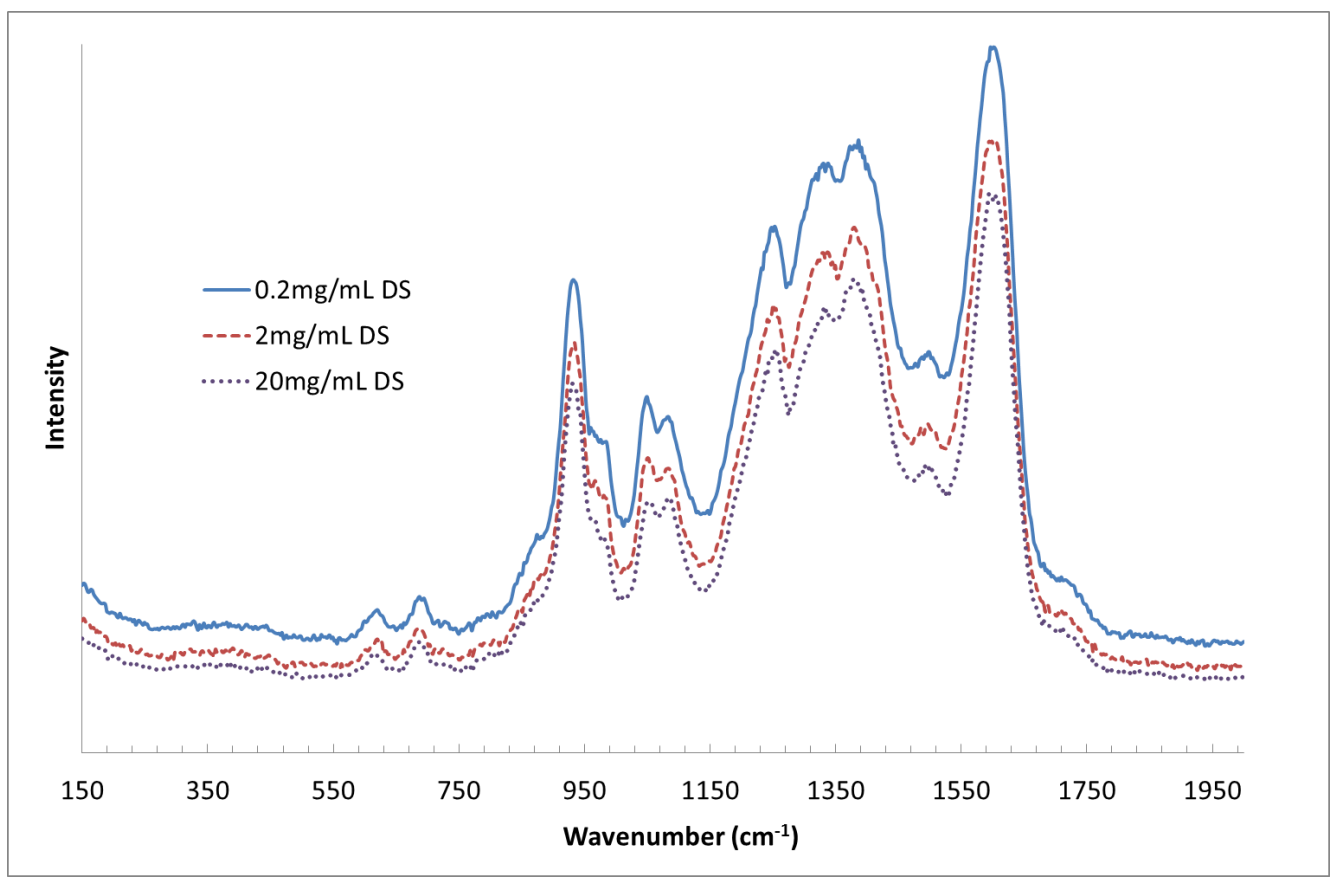

Supplemental Figure B. Comparison of PPy-DS Modulus Measurements using Force Mode Spectroscopy AFM and QCM-D

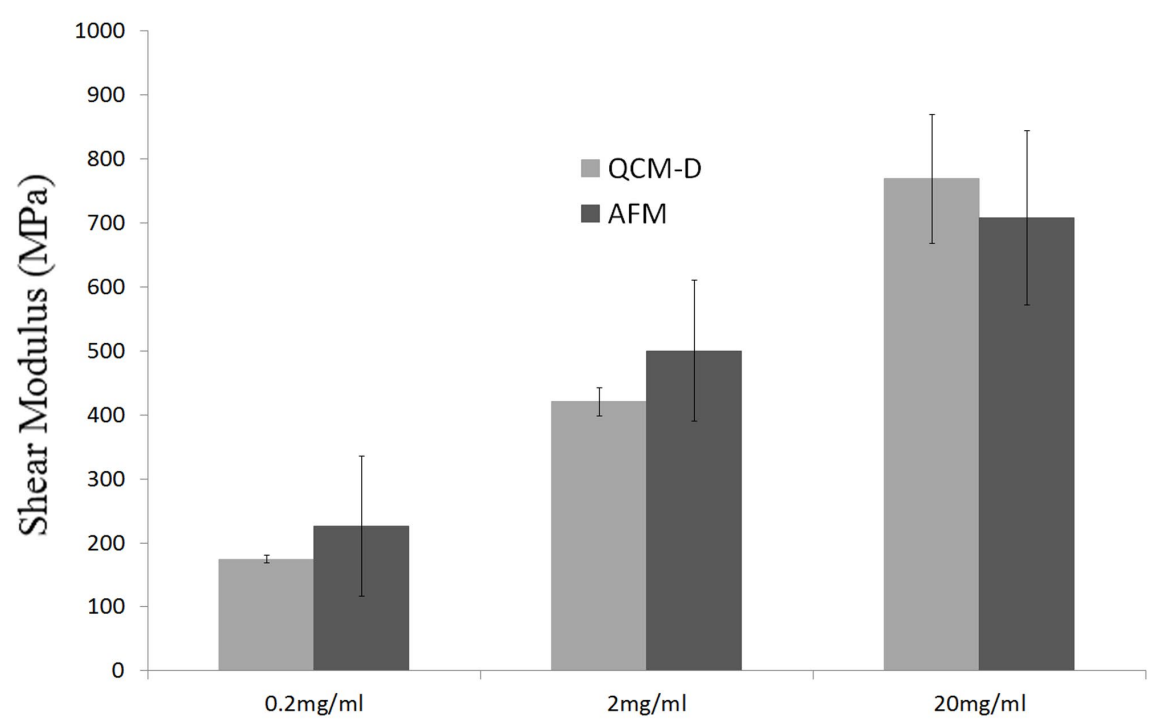

Figure S2: Shear Modulus values for PPy-DS films of varying DS concentration generated by from both modelled QCM-D data, or converting Young's Modulus measurements using Force Spectroscopy mode AFM to 
Shear modulus, thus allowing direct comparison of measurements from both techniques. Error bars represent $95 \%$ confidence intervals around the mean. 